\title{
Non-Vitamin K Oral Anticoagulants in Adults with Congenital Heart Disease: A Systematic Review
}

\author{
Nikolaos Stalikas ${ }^{1,2}$, Ioannis Doundoulakis ${ }^{1,3}$, Efstratios Karagiannidis ${ }^{1}($, \\ Emmanouil Bouras ${ }^{4}$, Anastasios Kartas ${ }^{1}{ }^{(0)}$, Alexandra Frogoudaki ${ }^{5}$, Haralambos Karvounis ${ }^{1}$, \\ Konstantinos Dimopoulos ${ }^{6}(\mathbb{D})$ and George Giannakoulas ${ }^{1, *(1)}$ \\ 1 First Department of Cardiology, AHEPA Hospital, Aristotle University of Thessaloniki, \\ 54636 Thessaloniki, Greece; nstalik@gmail.com (N.S.); doudougiannis@gmail.com (I.D.); \\ stratoskarag@gmail.com (E.K.); tkartas@gmail.com (A.K.); hkarvounis@gmail.com (H.K.) \\ 2 Department of Internal Medicine, General Hospital of Edessa, 58200 Proastio, Greece \\ 3 Department of Cardiology, 424 General Military Training Hospital, 54124 Thessaloniki, Greece \\ 4 Department of Hygiene, Social-Preventive Medicine \& Medical Statistics, Medical School, Aristotle \\ University of Thessaloniki, 54124 Thessaloniki, Greece; mpman33@gmail.com \\ 5 Second Department of Cardiology, Attikon University Hospital, University of Athens, 12462 Athens, Greece; \\ afrogou@otenet.gr \\ 6 Adult Congenital Heart Centre and National Centre for Pulmonary Hypertension, Royal Brompton Hospital \\ and Imperial College, London SW3 6NP, UK; k.dimopoulos@rbht.nhs.uk \\ * Correspondence: ggiannakoulas@auth.gr; Tel.: +30-2313303587
}

Received: 2 May 2020; Accepted: 4 June 2020; Published: 9 June 2020

check for updates

\begin{abstract}
Adults with congenital heart disease (ACHD) experience more thromboembolic complications than the general population. We systematically searched and critically appraised all studies on the safety and efficacy of non-vitamin-K oral anticoagulants (NOACs) in adult patients with various forms of congenital heart disease. PubMed and the Cochrane Central Register of Controlled Trials (CENTRAL) were used, with duplicate extraction of data and risk of bias assessment. The Newcastle-Ottawa quality assessment scale was used to assess study quality. Three studies fulfilled the inclusion criteria and were analyzed. The total number of participants was 766, with a total follow-up of 923 patient-years. The majority of patients $(77 \%)$ received a NOAC for atrial arrhythmias, while the remainder were prescribed NOACs for secondary (19\%) or primary $(4 \%)$ thromboprophylaxis. The annual rate of thromboembolic and major bleeding events was low: $0.98 \%$ (95\% CI: 0.51-1.86) and 1.74\% (95\% CI: 0.86-3.49) respectively. In Fontan patients, the annual rate of thromboembolic and major bleeding events was 3.13\% (95\% CI: $1.18-8.03)$ and 3.17\% (95\% CI: 0.15-41.39) respectively. NOACs appear safe and effective in ACHD without mechanical prostheses. Additional studies are, however, needed to confirm their efficacy in complex ACHD, especially those with a Fontan-type circulation.
\end{abstract}

Keywords: congenital heart defects; anticoagulants; thromboembolism; hemorrhage; treatment efficacy; patient safety

\section{Introduction}

Adults with congenital heart disease (ACHD) are a rapidly growing population, both in number and age, and are at increased risk of thromboembolic complications, especially strokes, compared to the general population [1-4]. Thromboembolic events are multifactorial in this population and are influenced by the complexity of the congenital heart disease (CHD), presence of cyanosis, repair status, prosthetic valves and other material, and residual lesions [4-9]. Moreover, supraventricular arrhythmias are common in ACHD patients, and the rise in prevalence is strongly related to aging, as well as 
to the number and type of previous interventions, and the effects of long-standing hemodynamic lesions [10,11].

With limited evidence to support clinical decision-making in ACHD, current indications for the use of anticoagulants in these patients are mainly based on expert opinion. The Pediatric and Congenital Electrophysiology Society and Heart Rhythm Society (PACES/HRS) Expert Consensus Statement on the Recognition and Management of Arrhythmias in Adults with Congenital Heart Disease advises long-term anticoagulation in patients with recurrent or sustained intra-atrial reentrant tachycardia, or atrial fibrillation (AF) in the presence of moderate or complex CHD (class IIa and I indication respectively) [12]. The anticoagulants of choice in these situations are vitamin $\mathrm{K}$ antagonists (VKA), as data on the safety and efficacy of non-vitamin $\mathrm{K}$ oral anticoagulants (NOACs) are limited. This consensus statement did, however, recommend the use of NOACs in patients with intra-atrial reentrant tachycardia or atrial fibrillation and simple nonvalvular CHD (class IIb indication). The routine administration of NOACs in patients with a Fontan circulation was felt to be contraindicated (class III indication), as evidence is lacking. Moreover, the $\mathrm{CHA}_{2} \mathrm{DS}_{2}$-VASc (congestive heart failure, hypertension, age 65-74 years, diabetes mellitus, sex-female, (1 point for the presence of each) and age $>75$ years, Stroke/TIA ( 2 points); range from 0 to 9) and HAS-BLED (uncontrolled systolic blood pressure $>\mathrm{r} 160 \mathrm{~mm} \mathrm{Hg}$, abnormal renal and/or liver function, previous stroke, bleeding history or predisposition, labile international normalized ratios, elderly, and concomitant drugs and/or alcohol excess ( 1 point for the presence of each); range from 0 to 9) scores, which are validated to assess stroke and bleeding risk respectively in patients with nonvalvular AF in the general population, are of unclear value in the ACHD population [13-15].

Recently, new evidence has emerged on the role of NOACs in ACHD patients with an indication for thromboprophylaxis [16,17]. Indeed, the potential advantages of NOACs in this young population are multiple, including ease-of-use and avoidance of periods of over- or under-anticoagulation in patients that are likely to remain anticoagulated for very long periods. We systematically collected all available evidence on the use of NOACs in various types of ACHD, aiming to assess the safety and efficacy of this medication in this population.

\section{Materials and Methods}

This systematic review followed the recommendations of the PRISMA statement [18]. All research was conducted according to a protocol registered in the PROSPERO database (PROSPERO registration number: CRD42020158227 review protocol available in https://www.crd.york.ac.uk/prospero/display_ record.php?RecordID=158227).

\subsection{Search Strategy}

PubMed and Cochrane Central Register of Controlled Trials (CENTRAL) were used for all searches from inception to November 2019. We also searched for randomized clinical trials in the U.S. National Library of Medicine's registry of clinical trials [19]. A basic search strategy was developed for PubMed and modified accordingly for other research engines. We also searched Prospero for a similar systematic review in progress, to avoid duplication. The PubMed and Cochrane Central strategy is presented in the Appendix A. The search was conducted by two independent investigators (NS, ID).

\subsection{Eligibility Criteria}

We included studies that assessed the efficacy and/or safety of NOACs in ACHD patients with an indication of thromboprophylaxis (atrial arrhythmias, primary, or secondary thromboprophylaxis). In this systematic review, ACHD patients were classified according to the severity of their congenital heart defect, as stated in the Task Force 1 of the 23rd Bethesda Conference [20]. Safety was reported as the rate of major bleeding events, in accordance with the criteria provided by the International Society on Thrombosis and Hemostasis [21]. Animal studies, case reports, reviews, and studies in children were excluded (Table 1). 
Table 1. Eligibility Criteria.

\begin{tabular}{ll}
\hline Inclusion Criteria & Exclusion Criteria \\
\hline ACHD patients of any disease severity & Animal Studies \\
\hline $\begin{array}{l}\text { ACHD patients receiving NOAC for: } \\
\text { - Atrial arrhythmias (Intra-atrial reentrant }\end{array}$ & Pediatric Population \\
tachycardia, AF, atrial flutter) & $\begin{array}{l}\text { ACHD patients with severe thrombocytopenia or } \\
\text { - Primary thromboprophylaxis }\end{array}$ \\
- Secondary thromboprophylaxis & \\
\hline
\end{tabular}

Abbreviations: ACHD: adults with congenital heart disease; AF: atrial fibrillation.

\subsection{Selection of Studies}

All studies were imported into a reference management software. After removal of duplicates, the two investigators (NS, ID) independently screened all titles. Studies that were eligible based on the title and abstract, were screened as full text by the reviewers. There was no disagreement between the two reviewers regarding abstract selection, so a third reviewer (EK) was not necessary.

\subsection{Quality Assessment}

The quality of the eligible studies was evaluated by two independent reviewers (NS, ID) using a version of the Newcastle-Ottawa scale (NOS, Universities of Newcastle, Australia and Ottawa, Canada) quality assessment scale for observational studies, as only cohort studies were included in this systematic review [22]. The risk of bias assessment was carried out by the same reviewers (NS, ID), with no disagreements between them.

\subsection{Data Extraction}

The two reviewers independently extracted the following data: number of patients in the study, study population, mean age, gender, type of congenital heart disease, type of surgery (in case of operated CHD), indication for anticoagulation, type of oral anticoagulation administered, mean duration of follow up in patient-years, incidence of thromboembolic events, severe bleeding events, and $\mathrm{CHA}_{2} \mathrm{DS}-\mathrm{VA}_{2} \mathrm{Sc}$ and HAS-BLED scores.

\subsection{Data Synthesis-Statistics}

Although the studies had inherent differences (such as different case mix and different follow-up periods), the population (ACHD) and the core of the intervention (i.e., use of NOACs in ACHD patients with an indication of thromboprophylaxis) was similar. Hence, we presented pooled statistics. We performed a random-effects meta-analysis using a generalized linear mixed model [23] and Clopper-Pearson confidence intervals for individual studies [24]. We preferred a generalized linear mixed model over a Freeman-Tukey double arcsine transformation due to potential methodological concerns regarding the back-transformation of meta-analysis results with the latter when individual study sizes differ significantly [25]. The analysis was performed in R version 3.6.0 [26], utilizing the meta package [27].

\section{Results}

A total of 89 studies were identified (69 on PubMed and 20 on CENTRAL). Of these, 85 were excluded based on their title and abstract (Figure 1, PRISMA flow diagram of the methodology). Of the four studies that were assessed for eligibility by full-text screening, one was excluded. Ultimately, three studies fulfilled the inclusion criteria and were assessed for quality. All studies were written in English. Details of the quality assessment process and results are presented in Table 2. 


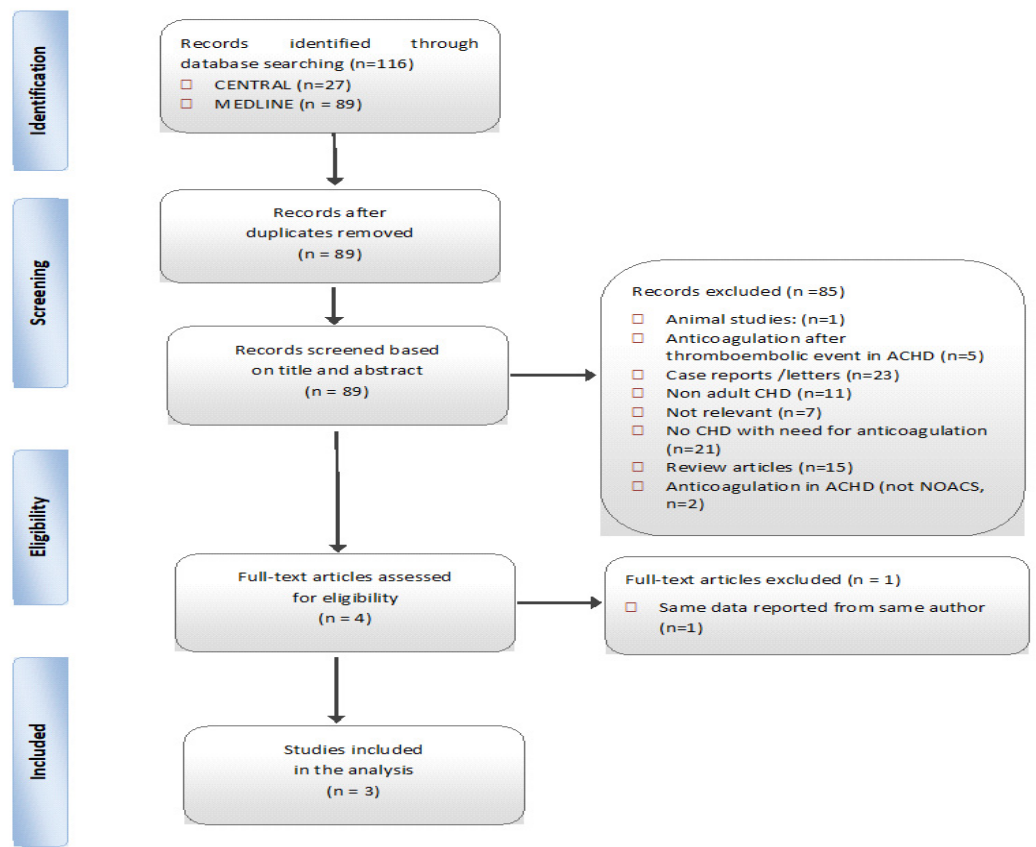

Figure 1. Summary of evidence of search and selection. Abbreviations: ACHD: adults with congenital heart disease; CHD: congenital heart disease, NOACs: non-vitamin-K oral anticoagulants.

Table 2. Quality assessment using the Newcastle-Ottawa scale.

\begin{tabular}{|c|c|c|c|c|c|c|c|c|c|c|}
\hline Study & $\begin{array}{l}\text { Cohort } \\
\text { Representativeness }\end{array}$ & $\begin{array}{c}\text { Selection of } \\
\text { Non-Exposed } \\
\text { Cohort }\end{array}$ & $\begin{array}{l}\text { Ascertainment } \\
\text { of Exposure }\end{array}$ & $\begin{array}{c}\text { The Outcome } \\
\text { of Interest Not } \\
\text { Present }\end{array}$ & $\begin{array}{l}\text { Comparability } \\
\text { of Cohorts }\end{array}$ & $\begin{array}{l}\text { Assessment of } \\
\text { Outcome }\end{array}$ & $\begin{array}{l}\text { Follow-Up } \\
\text { Long Enough }\end{array}$ & $\begin{array}{l}\text { Adequacy of } \\
\text { Follow Up of } \\
\text { Cohorts }\end{array}$ & $\begin{array}{l}\text { Total } \\
\text { Score }\end{array}$ & $\begin{array}{l}\text { Quality of } \\
\text { Study }\end{array}$ \\
\hline $\begin{array}{l}\text { Yang et al. } \\
\text { [28] }\end{array}$ & * & no & * & * & $*$ & * & $*$ & * & 7 & medium \\
\hline $\begin{array}{l}\text { Pujol et al. } \\
\text { [29] }\end{array}$ & * & no & $*$ & $*$ & no & * & $*$ & $*$ & 6 & medium \\
\hline $\begin{array}{l}\text { Georgekutty } \\
\text { et al. [30] }\end{array}$ & $*$ & no & * & $*$ & no & $*$ & $*$ & $*$ & 6 & medium \\
\hline
\end{tabular}

* high quality choice. 


\subsection{Cumulative Data and Individual Study Characteristics}

The characteristics of the included studies and their endpoints are depicted in Table 3. The total number of participants in the three included studies was 766, and the total duration of follow-up was 923.1 patient-years. ACHD patients of various types and complexity were included, but the primary endpoint was similar. The vast majority $(77 \%)$ of patients received a NOAC due to atrial arrhythmias (Table 4), followed by $19 \%$ of patients who were prescribed a NOAC for secondary thromboprophylaxis (following pulmonary embolism, deep vein thrombosis, systemic embolism, intracardiac thrombus, ischemic stroke, myocardial infarction due to paradoxical embolism). Only $4 \%$ of patients were prescribed NOACs for primary thromboprophylaxis (e.g., Fontan palliation or a cyanotic defect).

Pujol et al. [29] examined the use of NOACs in 215 ACHD patients. In this cohort, $44 \%$ of the total population had complex CHD, including 12 patients (5.6\%) with a Fontan circulation, and 17 patients $(7.9 \%)$ with chronic cyanosis. Most patients were anticoagulated with rivaroxaban (54.2\%), followed by apixaban $(32.2 \%)$, dabigatran $(9.3 \%)$, and edoxaban (3.7\%). Almost 1 out of 10 patients $(n=24)$, received concomitant treatment with aspirin, one was treated with clopidogrel, whereas three patients received dual antiplatelet treatment with aspirin and clopidogrel. The mean age was $48.4 \pm 15.4$ years and the mean follow up was $15.8 \pm 15.8$ months. Follow-up information was obtained using a detailed medical questionnaire that was mailed to all patients. Many patients received anticoagulation treatment for more than one indication (e.g., atrial arrhythmias and stroke/transient ischemic attack). In two-thirds of the patients $(n=143)$, the primary indication for anticoagulation was atrial arrhythmias (AF $69 \%$, atrial flutter $31 \%$ ), $54 \%$ received a NOAC for secondary thromboprophylaxis and $5.6 \%$ for primary thromboprophylaxis in the presence of a Fontan circulation. The $\mathrm{CHA}_{2} \mathrm{DS}_{2}$-VASc and HAS-BLED scores were calculated in all patients: $49.3 \%$ had a $\mathrm{CHA}_{2} \mathrm{DS}_{2}$-VASc $\geq 2$, and $87.5 \%$ a HAS-BLED score $\leq 2$. During follow-up, two thromboembolic events were reported in patients to whom a NOAC was prescribed for primary thromboprophylaxis and nine major bleeding events occurred (Table 5). The rate of thromboembolic and major bleeding events per patient-year was $0.7 \%$ and $3.1 \%$ respectively. For the few patients in this cohort who received concomitant antiplatelet treatment, bleeding risk was not found to be increased in univariate analysis (HR 3.18, CI (0.89-11.4), $p=0.08$ ). Finally, multivariate analysis showed that renal disease, which was present in almost $4 \%$ of the total population, was identified as the only major risk factor for major bleeding (HR: 13.75, CI: 2.60-72.54, $p=0.002$ ).

Georgekutty et al. [30] reported the first retrospective data on the efficacy and safety of NOACs in patients with a Fontan-type circulation ( $76 \%$ had a total cavopulmonary connection). In this study, 21 adult patients with Fontan circulation were prescribed a NOAC either for primary or secondary thromboprophylaxis (apixaban 63\%, dabigatran 18.5\%, rivaroxaban 18.5\%). Specifically, 57\% of patients received a NOAC due to atrial arrhythmias, $9.7 \%$ due to persistent right-to-left shunts, and $33.3 \%$ because of prior thrombotic events. All patients were treated with warfarin before NOAC initiation; the main reasons for the change in anticoagulant were either patient/provider preference, suboptimal international normalized ratio (INR) control, initiation of therapy elsewhere, or history of poor clinical follow-up. The $\mathrm{CHA}_{2} \mathrm{DS}_{2}$-VASc and HAS-BLED scores were calculated in all patients: a $\mathrm{CHA}_{2} \mathrm{DS}_{2}-\mathrm{VASc} \geq 2$ was present in $42.9 \%$ of patients, while all patients had a HAS-BLED score $\leq 2$. During a cumulative follow-up of 316 patient-months, one thrombotic event occurred in a 21-year-old "failing Fontan" patient with protein-losing enteropathy, who developed deep vein thrombosis after 12.6 months of treatment with dabigatran. No major bleeding events were reported, but 10 patients experienced minor bleeding (minor bleeding event rate of $38 \%$ per patient-year). Finally, one death occurred in a patient with multiorgan system failure after a out-of-hospital cardiac arrest.

Yang et al. [28] reported on the results of the NOTE registry, the first international multicenter cohort study assessing the safety and efficacy of NOACs (rivaroxaban $43 \%$; apixaban $39 \%$; dabigatran $12 \%$; edoxaban $7 \%)$ in ACHD patients. A quarter of patients $(28 \%, n=150)$ were previously on Vitamin $\mathrm{K}$ Antagonist (VKA) therapy and served as historic controls. The total duration of follow-up was 613 patient-years, with a median treatment duration of 1.0 (IQR 0.0-2.0) year, while in the VKA historical cohort this was 3.8 (IQR: 1.1-8.6) years. The investigators also assessed adherence to treatment and the 
effect of NOACs on quality of life (QoL). A total of 530 patients with ACHD of various complexities were included. Almost $15 \%$ of patients $(n=74)$ had a Fontan-type circulation, $65 \%$ of whom had a total cavopulmonary connection. A $\mathrm{CHA}_{2} \mathrm{DS}_{2}$-VASc $\geq 2$ was present in $46 \%$ and an HAS-BLED $\leq 2$ in $95 \%$. Indications for anticoagulation included atrial arrhythmias $(91 \%, n=481$, (AF 58\%, atrial flutter $40 \%$ and atrial tachycardia $2 \%)$ ), primary $(3 \%, n=17)$, and secondary thromboprophylaxis $(6 \%, n=32)$. All predefined endpoints were assessed by an expert investigator or site coordinator. There were six (1.1\%) thromboembolic events reported, with a rate of $1.0 \%$ per year (95\% CI: $0.4-2.0$ ). All thromboembolic events occurred in patients with moderate or severe forms of ACHD, and $50 \%$ $(n=3)$ were in patients with a Fontan circulation. Major bleeding events occurred in seven patients, i.e., $1 \%$ per year $(95 \%$ CI: $0.5-2.2)$ and $43 \%$ of major bleeds $(n=3)$ occurred in Fontan patients. Minor bleeding events were reported in 37 patients, with an estimated rate of $6.3 \%$ per year (95\% CI: 4.5-8.5). In terms of adherence to treatment during follow-up, 80-93\% of patients had sufficient adherence (assessed with the Morisky-8-questionnaire or using pharmacy interrogation data). Moreover, 33 prior VKA users reported an improvement in QoL in six out of eight domains $(p<0.05)$, while VKA-naïve patients $(n=39)$ reported no decline in QoL.

\subsection{Cumulative Results}

The annual incidence of thromboembolic and major bleeding events in the overall population was low: $0.98 \%$ (95\% CI: $0.51-1.86, n=9$ thromboembolic events) and $1.74 \%$ (95\% CI: $0.86-3.49, n=16$ major bleeding events) respectively (see Appendix A, Figures A1 and A2). The majority of thromboembolic events (4/9) and major bleeds (3/16) occurred in patients with a Fontan circulation $(n=107$, Tables 5 and 6), corresponding to an annual rate of thromboembolic events of 3.13\% (95\% CI: 1.18-8.03) and an annual rate of major bleeding events of $3.17 \%$ (95\% CI: 0.15-41.39). Of the four thromboembolic events in Fontan patients, only one was systemic (ischemic stroke); the remainder were pulmonary embolisms $(n=1)$, deep vein thrombosis $(n=1)$, and intracardiac thrombosis $(n=1)$. The most commonly used NOAC was rivaroxaban (45\%), followed by apixaban (38\%), dabigatran (12\%) and edoxaban (5\%). Of 9 thromboembolic events, 2 occurred in patients treated with rivaroxaban (2/349), 3 to those on dabigatran (3/89), and 4 to those on apixaban (4/293). Most major bleeding events ( 9 out of 16) occurred in patients treated with rivaroxaban (9/349), followed by those on apixaban ( $n=6$ major bleeds, 6/293), one major bleed occurred in a patient anticoagulated with edoxaban (1/35) and none in those treated with dabigatran (0/89). Since the event rate was low, direct comparisons between the different effects of NOACs or anatomical subgroups were not performed. No fatal event reported related to thromboembolism or major bleeding during follow-up. Of note, the median $\mathrm{CHA}_{2} \mathrm{DS}_{2}$-VASc score of patients who suffered a thromboembolic event was 1.0.

Table 3. Specific characteristics of the included studies and their endpoints.

\begin{tabular}{cccccc}
\hline Author & Year & Type of Study & Total Patients & $\begin{array}{c}\text { Total } \\
\text { Patient-Years } \\
\text { of Follow-Up }\end{array}$ & Primary Endpoint \\
\hline Yang et al. [28] & 2019 & Prospective Cohort & 530 & 613 & $\begin{array}{c}\text { Thromboembolism and major } \\
\text { bleeding }\end{array}$ \\
\hline Pujol et al. [29] & 2019 & Retrospective Cohort & 215 & 283.8 & $\begin{array}{c}\text { Thromboembolism and major, } \\
\text { minor bleeding }\end{array}$ \\
\hline $\begin{array}{c}\text { Georgekutty } \\
\text { et al. [30] }\end{array}$ & 2018 & Retrospective Cohort & 21 & 26.3 & $\begin{array}{c}\text { Thromboembolism and major, } \\
\text { non-major and minor bleeding }\end{array}$ \\
\hline
\end{tabular}


Table 4. Descriptive characteristics of included studies.

\begin{tabular}{|c|c|c|c|c|c|c|c|c|c|c|c|c|}
\hline \multirow[t]{2}{*}{ Author } & \multirow{2}{*}{$\begin{array}{l}\text { Male Sex } \\
\quad(\%)\end{array}$} & \multirow{2}{*}{$\begin{array}{l}\text { Age (Years) } \\
\text { mean } \pm \text { SD }\end{array}$} & \multicolumn{3}{|c|}{$\begin{array}{c}\text { Indication } \\
\text { for Anticoagulation (\%) }\end{array}$} & \multicolumn{3}{|c|}{ Severity of ACHD (\%) } & \multirow{2}{*}{$\begin{array}{c}\text { Thrombotic } \\
\text { Events } \\
n(\%)\end{array}$} & \multirow{2}{*}{$\begin{array}{c}\text { Bleeding } \\
\text { Events } n(\%)\end{array}$} & \multirow{2}{*}{$\begin{array}{l}\text { CHA2ADSVA2Sc } \\
\quad \geq 2(\%)\end{array}$} & \multirow{2}{*}{$\begin{array}{l}\text { HAS-BLED } \\
\quad \leq 2(\%)\end{array}$} \\
\hline & & & AA & PTP & STP & Simple & Moderate & Complex & & & & \\
\hline $\begin{array}{l}\text { Yang et al. } \\
\text { [28] }\end{array}$ & $55 \%$ & $47.0 \pm 15.0$ & 90.8 & 3.2 & 6.0 & 14.9 & 45.1 & 40.0 & $6(1.1)$ & $7(1.3)$ & 46.4 & 95.0 \\
\hline $\begin{array}{l}\text { Pujol et al. } \\
\text { [29] }\end{array}$ & $48 \%$ & $48.4 \pm 15.4$ & $66.8^{*}$ & $5.6^{*}$ & $42.9 *$ & 32.1 & 23.7 & 44.2 & $2(0.7)$ & $9(3.1)$ & 49.3 & 87.5 \\
\hline $\begin{array}{l}\text { Georgekutty } \\
\text { et al. [30] }\end{array}$ & $47 \%$ & $33.5 \pm 8.0$ & 57.0 & 9.5 & 33.3 & - & - & 100 & $1(4.76)$ & 0 & 42.9 & 100 \\
\hline
\end{tabular}

Abbreviations: AA: atrial arrhythmias; PTP: primary thromboprophylaxis; STP: secondary thromboprophylaxis. ${ }^{*}$ Many patients had more than one indication for anticoagulation treatment (e.g., atrial arrhythmias and stroke/transient ischemic attack).

Table 5. Descriptive characteristics of patients with thromboembolic events.

\begin{tabular}{|c|c|c|c|c|c|c|c|c|c|c|}
\hline Study & $\begin{array}{l}\text { Patients } \\
(n=9)\end{array}$ & Sex & Age & ACHD Type & NOAC * & Thromboembolic Event & Indication & $\begin{array}{c}\text { CHA2DS2 } \\
\text {-VASc }\end{array}$ & $\begin{array}{l}\text { HAS } \\
\text {-BLED }\end{array}$ & $\begin{array}{c}\text { Risk Factors and } \\
\text { Comorbidities }\end{array}$ \\
\hline $\begin{array}{c}\text { Georgekutty } \\
{[30]}\end{array}$ & 1 & M & 21 & Fontan & $\begin{array}{l}\text { Dabigatran } \\
110 \mathrm{mg} \text { b.i.d }\end{array}$ & Deep Vein Thrombosis & $\begin{array}{c}\text { Persistent } \\
\text { Right-to-Left Shunt }\end{array}$ & 1 & 0 & $\begin{array}{l}\text { Protein-losing } \\
\text { enteropathy }\end{array}$ \\
\hline Yang [28] & 2 & M & 30 & $\begin{array}{l}\text { Coronary } \\
\text { atriovenous } \\
\text { fistula }\end{array}$ & Dabigatran & Deep Vein Thrombosis & Atrial Arrhythmias & 3 & 2 & $\begin{array}{c}\text { Severe Tricuspid } \\
\text { Regurgitation }\end{array}$ \\
\hline Yang [28] & 3 & M & 42 & Fontan & Apixaban & Pulmonary Embolism & Atrial Arrhythmias & 0 & 3 & - \\
\hline Yang [28] & 4 & M & 25 & Fontan & Rivaroxaban & Intracardiac Thrombus & Atrial Arrhythmias & 2 & 1 & - \\
\hline Yang [28] & 5 & M & 44 & Tetralogy Fallot & Apixaban & Pulmonary Embolism & Atrial Arrhythmias & 1 & 1 & - \\
\hline Yang [28] & 6 & M & 23 & Fontan & Apixaban & Ischemic Stroke & Atrial Arrhythmias & 1 & 0 & - \\
\hline Yang [28] & 7 & $\mathrm{~F}$ & 25 & $\begin{array}{c}\text { Transposition of } \\
\text { Great Arteries }\end{array}$ & Apixaban & Intracardiac Thrombus & Atrial Arrhythmias & 4 & 0 & $\begin{array}{c}\text { Severe Tricuspid } \\
\text { Regurgitation }\end{array}$ \\
\hline Pujol [29] & 8 & M & 51 & VSD (corrected) & $\begin{array}{l}\text { Dabigatran } \\
150 \text { mg b.i.d }\end{array}$ & Stroke & $\begin{array}{c}\text { Primary } \\
\text { Thromboprophylaxis }\end{array}$ & 3 & 3 & $\begin{array}{c}\text { Stroke, TIA, Liver } \\
\text { Disease, Arterial } \\
\text { Hypertension }\end{array}$ \\
\hline Pujol [29] & 9 & M & 50 & $\begin{array}{c}\text { Aortic } \\
\text { Aneurysm }\end{array}$ & $\begin{array}{c}\text { Rivaroxaban } \\
20 \text { mg q.d }\end{array}$ & Deep Vein Thrombosis & $\begin{array}{c}\text { Primary } \\
\text { Thromboprophylaxis }\end{array}$ & 1 & 1 & $\begin{array}{c}\text { Arterial } \\
\text { Hypertension }\end{array}$ \\
\hline
\end{tabular}


Table 6. Descriptive characteristics of patients with major bleeding events.

\begin{tabular}{|c|c|c|c|c|c|c|c|c|c|c|}
\hline Study & $\begin{array}{l}\text { Patients } \\
(n=16)\end{array}$ & Sex & Age & ACHD type & NOAC * & $\begin{array}{l}\text { Bleeding } \\
\text { Location }\end{array}$ & Indication & CHA2D2-VASC & HAS-BLED & $\begin{array}{l}\text { Risk Factors and } \\
\text { Comorbidities }\end{array}$ \\
\hline Yang [28] & 1 & $\mathrm{~F}$ & 56 & Fontan & Apixaban & Gastrointestinal & AtrialArrhythmia & 2 & 1 & Mitral Regurgitation \\
\hline Yang [28] & 2 & $\mathrm{~F}$ & 71 & PAPVC & Rivaroxaban & Gastrointestinal & AtrialArrhythmia & 3 & 1 & Tricuspid Regurgitation \\
\hline Yang [28] & 3 & $\mathrm{~F}$ & 23 & $\mathrm{CoA}$ & Rivaroxaban & Menorrhagia & AtrialArrhythmia & 2 & 0 & Bioprosthetic AVand PV \\
\hline Yang [28] & 4 & $\mathrm{~F}$ & 42 & Eisenmenger & Rivaroxaban & Menorrhagia & $\begin{array}{l}\text { Pulmonary } \\
\text { Embolism }\end{array}$ & 3 & 2 & - \\
\hline Yang [28] & 5 & $\mathrm{~F}$ & 41 & Fontan & Apixaban & Menorrhagia & $\begin{array}{c}\text { Atrial } \\
\text { Arrhythmia }\end{array}$ & 4 & 0 & $\begin{array}{l}\text { Mitral Valve } \\
\text { Regurgitation }\end{array}$ \\
\hline Yang [28] & 6 & $\mathrm{M}$ & 80 & ToF & Apixaban & Hematuria & AtrialArrhythmia & 4 & 1 & Pulmonary Stenosis \\
\hline Yang [28] & 7 & $\mathrm{~F}$ & 67 & Fontan & Rivaroxaban & Menorrhagia & AtrialArrhythmia & 2 & 2 & \\
\hline Pujol [29] & 8 & $\mathrm{M}$ & 59 & $\mathrm{PFO}$ & $\begin{array}{l}\text { Apixaban } 5 \\
\text { mg b.i.d }\end{array}$ & Cranial & РTP & 3 & 3 & $\begin{array}{l}\text { Aspirin Arterial } \\
\text { Hypertension }\end{array}$ \\
\hline Pujol [29] & 9 & $\mathrm{~F}$ & 48 & TGA-Mustard & $\begin{array}{l}\text { Rivaroxaban } \\
20 \mathrm{mg} \text { q.d }\end{array}$ & Cranial & РTP & 2 & 0 & Oral Contraception \\
\hline Pujol [29] & 10 & $\mathrm{M}$ & 26 & $\begin{array}{l}\text { PA + VSD, PH } \\
\text { Deletion 22q11 }\end{array}$ & $\begin{array}{l}\text { Rivaroxaban } \\
10 \mathrm{mg} \text { q.d }\end{array}$ & Gastrointestinal & PTP & 1 & 3 & $\begin{array}{l}\text { Renal Insufficiency, } \\
\text { Cyanosis, Bleeding } \\
\text { under VKA }\end{array}$ \\
\hline Pujol [29] & 11 & $\mathrm{M}$ & 65 & ASD & $\begin{array}{l}\text { Apixaban } 2.5 \\
\text { mg b.i.d }\end{array}$ & Intraoccular & РTP & 3 & 2 & $\begin{array}{l}\text { Arterial Hypertension } \\
\text { Smoker }\end{array}$ \\
\hline Pujol [29] & 12 & $\mathrm{~F}$ & 44 & PA + VSDPAH & $\begin{array}{l}\text { Apixaban } 5 \\
\text { mg b.i.d }\end{array}$ & Intraarticular & РTP & 2 & 0 & $\begin{array}{l}\text { Renal Insufficiency, } \\
\text { Diabetes Mellitus }\end{array}$ \\
\hline Pujol [29] & 13 & $\mathrm{~F}$ & 46 & Marfan & $\begin{array}{l}\text { Rivaroxaban } \\
20 \mathrm{mg} \text { q.d }\end{array}$ & Intraarticular & РTP & 2 & 0 & Smoker \\
\hline Pujol [29] & 14 & $\mathrm{~F}$ & 43 & ASD & $\begin{array}{l}\text { Rivaroxaban } \\
20 \mathrm{mg} \text { q.d }\end{array}$ & Intramuscular & РTP & 1 & 0 & - \\
\hline Pujol [29] & 15 & $\mathrm{~F}$ & 34 & $\mathrm{PFO}$ & $\begin{array}{l}\text { Edoxaban } 60 \\
\text { mg q.d }\end{array}$ & Vaginal & РTP & 3 & 3 & Bleeding under VKA \\
\hline Pujol [29] & 16 & $\mathrm{~F}$ & 42 & VSD (corrected) & $\begin{array}{l}\text { Rivaroxaban } \\
20 \mathrm{mg} \text { q.d }\end{array}$ & Vaginal & РTP & 1 & 0 & - \\
\hline
\end{tabular}

Abbreviations: M: Male; F:Fem ventricular Septal defect; ASD: atrial septal defect; PTP: primary thromboprophylaxis; TGA: transposition of great arteries; AV: aortic valve; PV: pulmonary valve; b.i.d: twice a day; q.d; once a day. ${ }^{*}$ NOAC dose indicated where reported. 


\section{Discussion}

This is the first systematic review of studies that has investigated the efficacy and safety of NOACs in ACHD patients. The few studies available appear reassuring with regards to the safety of NOACS in the ACHD population, with a low major bleeding rate in patients with both simple and complex lesions. The evidence regarding the efficacy of NOACS in this population also appears encouraging, with a low thromboembolic event rate overall. The efficacy and safety data of NOACs in ACHD collected in this study do not appear to differ significantly from what is reported for VKAs in this population. Indeed, two retrospective studies in ACHD patients with atrial arrhythmias treated with VKAs reported a $1.1-1.3 \%$ annual rate of thromboembolic events and $0.8-4.4 \%$ annual rate of major bleeding events $[14,31]$. However, more data are needed for Fontan patients, who appear to have a higher event rate than the remainder.

The majority of patients included in the three analyzed studies had CHD of significant complexity, with one study (Georgekutty et al.) including only adults with a Fontan circulation. In the largest study (Yang et al.), 85.1\% of patients had CHD of moderate or high complexity, reflecting the population of patients with indications for anticoagulation in real life. Despite the high prevalence of complex CHD in the population included in this metanalysis, the incidence of thromboembolic events whilst on NOACs was low, with the exception perhaps of Fontan patients. Indeed, almost half of thromboembolic events during follow-up occurred in patients with a Fontan circulation. This can manifest as thrombosis of the Fontan and pulmonary circulation, with its slow, non-pulsatile flow, endothelial damage, hypercoagulability, or paradoxical emboli to the systemic circulation through a fenestration or collateral circulation [32-35]. NOACs may be insufficient to prevent thrombosis in some Fontan patients, especially those with older types of Fontan operations (atriopulmonary Fontan), in whom a severely enlarged right atrium, a low cardiac output state, and frequent arrhythmias may require a stronger anticoagulation regime. However, in a recent meta-analysis of Fontan patients receiving VKA (i.e., the current standard-of-care), the overall incidence of thromboembolism reached 10\% [36].

ACHD patients requiring anticoagulation are often young, and any decision on the type of anticoagulant prescribed should take into account their thrombotic risk, but also their life expectancy and the impact it could take on their lifestyle. NOACs possess many advantages in contrast to VKAs. They have a rapid onset of action, fewer drug and food interactions, predictable pharmacokinetics, and a shorter half-life [37]. Most importantly, NOACs do not require laboratory monitoring, making them more acceptable for younger active patients [38]. A recent cross-sectional study demonstrated high non-adherence rates or discontinuation of warfarin ( $26 \%$ and $17 \%$ respectively) in 127 young patients (mean age 31.2 years) after valve replacement surgery for rheumatic heart disease with a mean time since surgery of 3.7 years [39]. In general, adherence to NOACs is superior to VKAs [40], with one out of three patients who start warfarin for atrial fibrillation discontinuing treatment after one year of therapy [41-44]. Adherence to NOACs was also good ( $\geq 80 \%$ ) during the two years of follow-up in the NOTE registry. Optimal long-term adherence to treatment is likely to translate into a lower thromboembolic event rate, especially in younger ACHD patients who may need anticoagulation for decades.

Sample size restrictions and differences in population characteristics aside, the mean annual thromboembolism (0.98\%) and annual major-bleeding rates $(3.13 \%)$ reported in our study did not exceed those of any of the NOAC landmark trials [45-47]. Participants in our analyzed studies had low median HAS-BLED and $\mathrm{CHA}_{2} \mathrm{DS}_{2}$-VASc scores, which may explain the low overall incidence of thromboembolic and bleeding events. However, the mechanisms behind thrombotic events in ACHD patients often differ to those of the general population and patients with acquired heart disease, and there is no firm evidence on the accuracy of these scores in the ACHD population. In a retrospective cohort study of $482 \mathrm{ACHD}$ patients with atrial arrhythmias treated with oral anticoagulation or antiplatelet therapy, the $\mathrm{CHA}_{2} \mathrm{DS}_{2}$-VASc was unable to accurately predict thromboembolic events [14], while the severity of the underlying CHD (50\% with severe CHD) was associated with the thromboembolic risk. In another retrospective cohort study of 158 patients with atrial arrhythmias who were not 
anticoagulated, thromboembolic events were also observed in patients with low or intermediate $\mathrm{CHA}_{2} \mathrm{DS}_{2}$-VASc scores [15]. The CONCOR registry, which assessed the rate of thromboembolic and bleeding events in 229 ACHD patients with atrial arrhythmias, reported that ACHD patients with a HAS-BLED score $\geq 2$ receiving VKAs had an almost three-fold increased risk of a bleeding events compared to patients with a score $<2$ [31]. This suggests that the HAS-BLED score may have a role in the ACHD population, although more data are needed to confirm this finding.

This systematic review has several limitations. Only three observational studies met our inclusion criteria on the absence of randomized controlled trials and all scored a medium score of quality in the NOS. We used a generalized linear mixed model to pool prevalence rates which is considered to be advantageous over other approaches that are based on transformations (arcsine, and Freeman-Tukey double arcsine), when there are small sample sizes, nevertheless, due to the small number of ACHD patients examined in this systematic review, with various types of disease, firm conclusions cannot be drawn and the results cannot be applied directly in routine clinical practice. Ongoing studies are expected to fill more knowledge gaps regarding the efficacy and safety of NOACs in patients with CHD. A nationwide, prospective, multicenter, observational study is aiming to accumulate 500-patient-years of routine apixaban use in ACHD and atrial arrhythmias until the end of 2022 (NCT03854149). Two interventional prospective randomized controlled trials in Fontan pediatric patients are nearing completion in mid-2020. The first is examining rivaroxaban versus aspirin in 112 patients (NCT02846532); the other is studying 200 patients, to compare 3-arms: apixaban, VKA, and low-molecular-weight heparin (NCT02981472).

\title{
5. Conclusions
}

ACHD patients are a heterogeneous population, with often complex pathophysiology requiring specialist care and significant expertise when prescribing anticoagulants. Our systematic review suggests that NOACs are safe and effective in ACHD, even though stronger evidence is needed to confirm this, especially for more complex conditions, such as patients with a Fontan circulation.

Author Contributions: Conceptualization, N.S. and I.D.; methodology, N.S. and I.D; software, N.S. and I.D.; formal analysis, N.S. and I.D.; investigation, E.K.; resources, N.S. and I.D; writing-original draft preparation, A.K., H.K., A.F., K.D; writing-review and editing, A.K., H.K., A.F., K.D.; project administration, A.K., H.K., A.F., K.D and G.G; funding acquisition, A.K., H.K., A.F, K.D and G.G. And E.B. contributed in software and Formal analysis. All authors have read and agreed to the published version of the manuscript.

Conflicts of Interest: All authors state that they do not have any conflict of interest.

\section{Abbreviations}

$\begin{array}{ll}\text { ACHD } & \text { adult patients with congenital heart disease } \\ \text { CHD } & \text { congenital heart disease } \\ \text { VKA } & \text { Vitamin K antagonist } \\ \text { NOACs } & \text { Non-vitamin K oral anticoagulants } \\ \text { NOS } & \text { Newcastle-Ottawa scale } \\ \text { QoL } & \text { Quality of Life }\end{array}$

\section{Appendix A}

MEDLINE search strategy (last search 20/03/2020)

\author{
via PubMed \\ $\# 1$ \\ 1. Adult congenital heart disease \\ 2. Grown-up congenital heart disease \\ 3. Aortic stenosis \\ 4. Atrial septal defect \\ 5. Atrioventricular septal defect \\ 6. Bicuspid aortic valve \\ 7. Dextrocardia
}


8. Double inlet left ventricle

9. Double outlet right ventricle

10. Ebstein's anomaly

11. Hypoplastic left heart syndrome

12. Hypoplastic right heart syndrome

13. Mitral stenosis

14. Persistent truncus arteriosus

15. Pulmonary atresia

16. Pulmonary stenosis

17. Transposition of the great vessels

18. Tricuspid atresia

19. Ventricular septal defect (VSD)

20. New oral anticoagulants

21. NOACs

22. DOACs

23. Xarelto

24. Eliquis

25. Pradaxa

26. Rivaroxaban

27. Apixaban

28. Edoxaban

29. Dabigatran

30. Factor $X$ inhibitors

31. 1 OR 2 OR 3 OR 4 OR 5 OR 6 OR 7 OR 8 OR 9 OR 10 OR 11 OR 12 OR 13 OR 14 OR 15 OR 16 OR 17 OR 18 OR 19

32. 20 OR 21 OR 22 OR 23 OR 24 OR 25 OR 26 OR 27 OR 28 OR 29 OR 30

33. 31 AND 32

\section{\#2}

34. "Factor Xa Inhibitors" [MESH]

35. "Antithrombins" [MESH]

36. "Adult Congenital heart disease" [MESH]

37. 1 OR 2

38. 4 AND 5

\section{CENTRAL ( 20/03/2020)}

\#1 MeSH descriptor: [Heart Defects, Congenital] explode all trees \#2 MeSH descriptor: [Anticoagulants] explode all trees

\#3 1 AND \#2

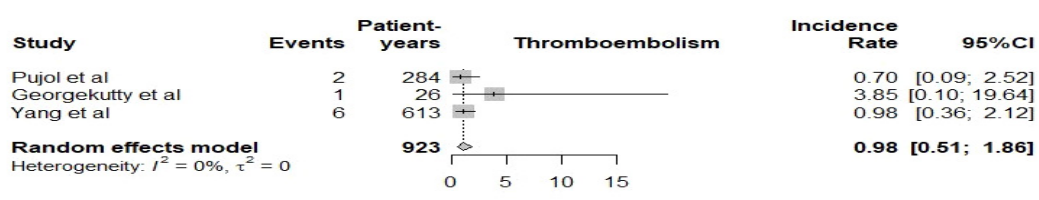

Figure A1. Forest plot of the incidence of thromboembolic events in ACHD patients.

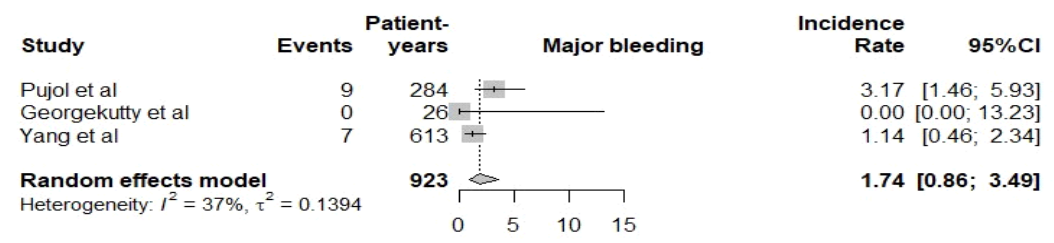

Figure A2. Forest plot of the incidence of major bleeding events in ACHD patients.

\section{References}

1. Yap, S.-C.; Harris, L.; Chauhan, V.S.; Oechslin, E.N.; Silversides, C.K. Identifying High Risk in Adults with Congenital Heart Disease and Atrial Arrhythmias. Am. J. Cardiol. 2011, 108, 723-728. [CrossRef] [PubMed] 
2. Verheugt, C.L.; Uiterwaal, C.S.P.M.; van der Velde, E.T.; Meijboom, F.J.; Pieper, P.G.; van Dijk, A.P.J.; Vliegen, H.W.; Grobbee, D.E.; Mulder, B.J.M. Mortality in adult congenital heart disease. Eur. Heart J. 2010, 31, 1220-1229. [CrossRef] [PubMed]

3. Engelfriet, P.; Boersma, E.; Oechslin, E.; Tijssen, J.; Gatzoulis, M.A.; Thilén, U.; Kaemmerer, H.; Moons, P.; Meijboom, F.; Popelová, J.; et al. The spectrum of adult congenital heart disease in Europe: Morbidity and mortality in a 5 year follow-up period. The Euro Heart Survey on adult congenital heart disease. Eur. Heart J. 2005, 26, 2325-2333. [CrossRef] [PubMed]

4. Lanz, J.; Brophy, J.M.; Therrien, J.; Kaouache, M.; Guo, L.; Marelli, A.J. Stroke in Adults with Congenital Heart Disease: Incidence, Cumulative Risk, and Predictors. Circulation 2015, 132, 2385-2394. [CrossRef]

5. Giannakoulas, G.; Boutsikou, M. The Gordian knot of thromboembolism in congenital heart disease. Heart 2015, 101, 1523-1524. [CrossRef]

6. Hoffmann, A.; Chockalingam, P.; Balint, O.H.; Dadashev, A.; Dimopoulos, K.; Engel, R.; Schmid, M.; Schwerzmann, M.; Gatzoulis, M.A.; Mulder, B.; et al. Cerebrovascular accidents in adult patients with congenital heart disease. Heart 2010, 96, 1223-1226. [CrossRef]

7. Brotschi, B.; Hug, M.I.; Latal, B.; Neuhaus, D.; Buerki, C.; Kroiss, S.; Spoerri, C.; Albisetti, M. Incidence and predictors of indwelling arterial catheter-related thrombosis in children. J. Thromb. Haemost. 2011, 9, 1157-1162. [CrossRef]

8. Diab, Y.A.; Ramakrishnan, K.; Alfares, F.A.; Hynes, C.F.; Chounoune, R.; Shankar, V.; Kanter, J.P.; Nath, D.S. Transcatheter Treatment of Thrombosis in the Single Ventricle Pathway: An Institutional Experience. Congenit. Heart Dis. 2016, 11, 39-44. [CrossRef]

9. Khairy, P.; Landzberg, M.J.; Gatzoulis, M.A.; Mercier, L.A.; Fernandes, S.M.; Lavoie, J.P.; Guerra, P.G.; Frogoudaki, A.; Walsh, E.P.; Dore, A.; et al. Transvenous pacing leads and systemic thromboemboli in patients with intracardiac shunts: A multicenter study. Circulation 2006, 113, 2391-2397. [CrossRef]

10. Bouchardy, J.; Therrien, J.; Pilote, L.; Ionescu-Ittu, R.; Martucci, G.; Bottega, N.; Marelli, A.J. Atrial arrhythmias in adults with congenital heart disease. Circulation 2009, 120, 1679-1686. [CrossRef]

11. Giannakoulas, G.; Dimopoulos, K.; Yuksel, S.; Inuzuka, R.; Pijuan-Domenech, A.; Hussain, W.; Tay, E.L.; Gatzoulis, M.A.; Wong, T. Atrial tachyarrhythmias late after Fontan operation are related to increase in mortality and hospitalization. Int. J. Cardiol. 2012, 157, 221-226. [CrossRef]

12. Khairy, P.; van Hare, G.F.; Balaji, S.; Berul, C.I.; Cecchin, F.; Cohen, M.I.; Daniels, C.J.; Deal, B.J.; Dearani, J.A.; De Groot, N.; et al. PACES/HRS Expert Consensus Statement on the Recognition and Management of Arrhythmias in Adult Congenital Heart Disease. Can. J. Cardiol. 2014, 30, 1-63. [CrossRef] [PubMed]

13. Lane, D.A.; Lip, G.Y.H. Use of the $\mathrm{CHA}_{2} \mathrm{DS}_{2}$-VASc and HAS-BLED Scores to Aid Decision Making for Thromboprophylaxis in Nonvalvular Atrial Fibrillation. Circulation 2012, 126, 860-865. [CrossRef] [PubMed]

14. Khairy, P.; Aboulhosn, J.; Broberg, C.S.; Cohen, S.; Cook, S.; Dore, A.; Fernandes, S.M.; Fournier, A.; Kay, J.; Levesque, S.; et al. Thromboprophylaxis for atrial arrhythmias in congenital heart disease: A multicenter study. Int. J. Cardiol. 2016, 223, 729-735. [CrossRef]

15. Masuda, K.; Ishizu, T.; Niwa, K.; Takechi, F.; Tateno, S.; Horigome, H.; Aonuma, K. Increased risk of thromboembolic events in adult congenital heart disease patients with atrial tachyarrhythmias. Int. J. Cardiol. 2017, 234, 69-75. [CrossRef]

16. Freisinger, E.; Koeppe, J.; Bronstein, L.; Makowski, L.; Reinecke, H.; Gerss, J.; Baumgartner, H.; Diller, G. P4161Oral anticoagulation in 13,344 adult patients with congenital heart disease (ACHD) in a longitudinal real-world setting in 2005-2017. Eur. Heart J. 2019, 40, ehz745. 0733. [CrossRef]

17. Yang, H.; Bouma, B.J.; Mulder, B.J.M. Is Initiating NOACs for Atrial Arrhythmias Safe in Adults with Congenital Heart Disease? Cardiovasc. Drugs Ther. 2017, 31, 413-417. [CrossRef]

18. Liberati, A.; Altman, D.G.; Tetzlaff, J.; Mulrow, C.; Gøtzsche, P.C.; Ioannidis, J.P.A.; Clarke, M.; Devereaux, P.J.; Kleijnen, J.; Moher, D. The PRISMA Statement for Reporting Systematic Reviews and Meta-Analyses of Studies That Evaluate Health Care Interventions: Explanation and Elaboration. PLoS Med. 2009, 6, 1-28. [CrossRef]

19. Home-ClinicalTrials.gov. Available online: https://clinicaltrials.gov/ (accessed on 17 April 2020).

20. Warnes, C.A.; Liberthson, R.; Danielson, G.K.; Dore, A.; Harris, L.; Hoffman, J.I.; Somerville, J.; Williams, R.G.; Webb, G.D. Task force 1: The changing profile of congenital heart disease in adult life. J. Am. Coll. Cardiol. 2001, 37, 1170-1175. [CrossRef] 
21. Schulman, S.; Anger, S.U.; Bergqvist, D.B.; Lassen, M.R.; Fisher, W. Definition of major bleeding in clinical investigations of antihemostatic medicinal products in surgical patients. J. Thromb. Haemost. 2010, 8, $202-204$. [CrossRef]

22. Wells, G.A.; Shea, B.; O'Connell, D.; Peterson, J.; Welch, V.; Losos, M.; Tugwell, P. The Newcastle-Ottawa Scale (NOS) For Assessing the Quality of Nonrandomised Studies in Meta-analyses. 2013. Available online: http://www.ohri.ca/programs/clinical_epidemiology/oxford.asp (accessed on 20 March 2020).

23. Stijnen, T.; Hamza, T.H.; Özdemir, P. Random effects meta-analysis of event outcome in the framework of the generalized linear mixed model with applications in sparse data. Stat. Med. 2010, 29, 3046-3067. [CrossRef]

24. Julious, S.A. Two-sided confidence intervals for the single proportion: Comparison of seven methods by Robert G. Newcombe. Stat. Med. 2005, 24, 3383-3384. [CrossRef] [PubMed]

25. Schwarzer, G.; Chemaitelly, H.; Abu-Raddad, L.J.; Rucker, G. Seriously misleading results using inverse of Freeman-Tukey double arcsine transformation in meta-analysis of single proportions. Res. Synth. Methods 2019, 10, 476-483. [CrossRef] [PubMed]

26. R: The R Project for Statistical Computing. Available online: https://www.r-project.org/ (accessed on 12 April 2020).

27. Schwarzer, G.; Carpenter, J.R.; Rücker, G. Meta-Analysis. In Meta-Analysis with R; Springer, Cham: Basel, Switzerland, 2015; pp. 187-216.

28. Yang, H.; Bouma, B.J.; Dimopoulos, K.; Khairy, P.; Ladouceur, M.; Niwa, K.; Greutmann, M.; Schwerzmann, M.; Egbe, A.; Scognamiglio, G.; et al. Non-vitamin K antagonist oral anticoagulants (NOACs) for thromboembolic prevention, are they safe in congenital heart disease? Results of a worldwide study. Int. J. Cardiol. 2020, 299, 123-130. [CrossRef] [PubMed]

29. Pujol, C.; Müssigmann, M.; Schiele, S.; Nagdyman, N.; Niesert, A.C.; Kaemmerer, H.; Ewert, P.; Tutarel, O. Direct oral anticoagulants in adults with congenital heart disease-A single centre study. Int. J. Cardiol. 2020, 300, 127-131. [CrossRef]

30. Georgekutty, J.; Kazerouninia, A.; Wang, Y.; Ermis, P.R.; Parekh, D.R.; Franklin, W.J.; Lam, W.W. Novel oral anticoagulant use in adult Fontan patients: A single center experience. Congenit. Heart Dis. 2018, 13, 541-547. [CrossRef]

31. Heidendael, J.F.; Bokma, J.P.; de Groot, J.R.; Koolbergen, D.R.; Mulder, B.J.M.; Bouma, B.J. Weighing the risks: Thrombotic and bleeding events in adults with atrial arrhythmias and congenital heart disease. Int. J. Cardiol. 2015, 186, 315-320. [CrossRef]

32. Clift, P.; Celermajer, D. Managing adult Fontan patients: Where do we stand? Eur. Respir. Rev. 2016, 25, 438-450. [CrossRef]

33. Balling, G.; Vogt, M.; Kaemmerer, H.; Eicken, A.; Meisner, H.; Hess, J. Intracardiac thrombus formation after the Fontan operation. J. Thorac. Cardiovasc. Surg. 2000, 119, 745-752. [CrossRef]

34. Tsang, W.; Johansson, B.; Salehian, O.; Holm, J.; Webb, G.; Gatzoulis, M.A.; Therrien, J. Intracardiac thrombus in adults with the Fontan circulation. Cardiol. Young 2007, 17, 646-651. [CrossRef]

35. Khairy, P.; Fernandes, S.M.; Mayer, J.E.; Triedman, J.K.; Walsh, E.P.; Lock, J.E.; Landzberg, M.J. Long-term survival, modes of death, and predictors of mortality in patients with Fontan surgery. Circulation 2008, 117, 85-92. [CrossRef] [PubMed]

36. Alsaied, T.; Alsidawi, S.; Allen, C.C.; Faircloth, J.; Palumbo, J.S.; Veldtman, G.R. Strategies for thromboprophylaxis in Fontan circulation: A meta-analysis. Heart 2015, 101, 1731-1737. [CrossRef] [PubMed]

37. Mekaj, Y.H.; Mekaj, A.Y.; Duci, S.B.; Miftari, E.I. New oral anticoagulants: Their advantages and disadvantages compared with vitamin $\mathrm{K}$ antagonists in the prevention and treatment of patients with thromboembolic events. Ther. Clin. Risk Manag. 2015, 11, 967-977. [CrossRef] [PubMed]

38. Bauer, K.A. Pros and cons of new oral anticoagulants. Hematol. Am. Soc. Hematol. Educ. Progr. 2013, 2013, 464-470. [CrossRef]

39. Thomson Mangnall, L.J.; Sibbritt, D.W.; Al-Sheyab, N.; Gallagher, R.D. Predictors of warfarin non-adherence in younger adults after valve replacement surgery in the South Pacific. Heart Asia 2016, 8, 18-23. [CrossRef]

40. Tzikas, A.; Samaras, A.; Kartas, A.; Vasdeki, D.; Fotos, G.; Dividis, G.; Paschou, E.; Forozidou, E.; Tsoukra, P.; Kotsi, E.; et al. Motivational Interviewing to Support Oral AntiCoagulation adherence in patients with non-valvular Atrial Fibrillation (MISOAC-AF): A randomised clinical trial. Eur. Heart J. Cardiovasc. Pharmacother. 2020. [CrossRef] 
41. Raparelli, V.; Proietti, M.; Cangemi, R.; Lip, G.Y.H.; Lane, D.A.; Basili, S. Adherence to oral anticoagulant therapy in patients with atrial fibrillation focus on non-vitamin $\mathrm{k}$ antagonist oral anticoagulants. Thromb. Haemost. 2017, 117, 209-218.

42. Gallagher, A.M.; Rietbrock, S.; Plumb, J.; van Staa, T.P. Initiation and persistence of warfarin or aspirin in patients with chronic atrial fibrillation in general practice: Do the appropriate patients receive stroke prophylaxis? J. Thromb. Haemost. 2008, 6, 1500-1506. [CrossRef]

43. Fang, M.C.; Go, A.S.; Chang, Y.; Borowsky, L.H.; Pomernacki, N.K.; Udaltsova, N.; Singer, D.E. Warfarin discontinuation after starting warfarin for atrial fibrillation. Circ. Cardiovasc. Qual. Outcomes 2010, 3, 624-631. [CrossRef]

44. Gomes, T.; Mamdani, M.M.; Holbrook, A.M.; Paterson, J.M.; Juurlink, D.N. Persistence with therapy among patients treated with warfarin for atrial fibrillation. Arch. Intern. Med. 2012, 172, 1687-1689. [CrossRef]

45. Granger, C.B.; Alexander, J.H.; McMurray, J.J.V.; Lopes, R.D.; Hylek, E.M.; Hanna, M.; Al-Khalidi, H.R.; Ansell, J.; Atar, D.; Avezum, A.; et al. Apixaban versus Warfarin in Patients with Atrial Fibrillation. N. Engl. J. Med. 2011, 365, 981-992. [CrossRef] [PubMed]

46. Connolly, S.J.; Ezekowitz, M.D.; Yusuf, S.; Eikelboom, J.; Oldgren, J.; Parekh, A.; Pogue, J.; Reilly, P.A.; Themeles, E.; Varrone, J.; et al. Dabigatran versus Warfarin in Patients with Atrial Fibrillation. N. Engl. J. Med. 2009, 361, 1139-1151. [CrossRef] [PubMed]

47. Patel, M.R.; Mahaffey, K.W.; Garg, J.; Pan, G.; Singe, D.E.; Hacke, W.; Breithardt, G.; Halperin, J.L.; Hankey, G.J.; Piccini, J.P.; et al. Rivaroxaban versus Warfarin in Nonvalvular Atrial Fibrillation. N. Engl. J. Med. 2011, 365, 883-891. [CrossRef] [PubMed]

(C) 2020 by the authors. Licensee MDPI, Basel, Switzerland. This article is an open access article distributed under the terms and conditions of the Creative Commons Attribution (CC BY) license (http://creativecommons.org/licenses/by/4.0/). 